\title{
Assessment of Once Daily Sustained Release Hydrophilic Matrix Tablet of Carvedilol
}

\author{
Uttom Kumar, Md. Samiul Islam, Shimul Halder and Abu Shara Shamsur Rouf
}

Department of Pharmaceutical Technology, Faculty of Pharmacy, University of Dhaka Dhaka-1000, Bangladesh

(Received: August 29, 2016; Accepted: March 25, 2017; Published (web): June 21, 2017)

\begin{abstract}
The objective of the present study was to design and evaluate once daily sustained release tablet of carvedilol, using two molecular weight grades of hydrophilic polymers (methocel ${ }^{\mathbb{Q}} \mathrm{K} 4 \mathrm{M} \mathrm{CR}$ and methocel ${ }^{\mathbb{}} \mathrm{K} 15 \mathrm{M}$ $\mathrm{CR}$ ) as release retarding materials. Two sets of formulations were prepared, where first set of four formulations (F1F4) contained variable ratios of methoce ${ }^{\circledR} \mathrm{K} 4 \mathrm{M} \mathrm{CR}$ and methoce ${ }^{\circledR} \mathrm{K} 15 \mathrm{M}$ CR $(15 \%: 15 \%, 15 \%: 13 \%, 15 \%: 11 \%$ and $15 \%: 9 \%$ ) to optimize the composition of polymers in the tablet matrices such that the drug and polymer interaction was sufficient for sustaining release up to 24 hours and second set of five formulations (F5-F9) contained variable percentages of sodium lauryl sulfate (SLS) $(1.0,1.25,1.5,1.75$ and $2.0 \%)$ to enhance the dissolution rate of the drug from the tablet matrices because of its poor aqueous solubility. The tablets were prepared by direct compression method and evaluated for hardness, thickness, friability, weight variation and in vitro drug release. The in vitro dissolution studies were carried out in simulated gastric fluid $(900 \mathrm{ml}, \mathrm{pH} 1.2)$ for 24 hours using USP type II apparatus operated at $100 \mathrm{rpm}$ and $37 \pm 0.05^{\circ} \mathrm{C}$. The release profiles were explored and explained by zero order, first order, Higuchi, Korsmeyer-Peppas and Hixson-Crowell models. From this study, the drug release profiles for formulations F6 to F9 were found to be satisfactory and the release mechanism followed both diffusion and erosion. Due to lower percentage of SLS used, F6 was considered as the best formulation.
\end{abstract}

Key words: Carvedilol, Sustained release, Hydrophilic polymer, Dissolution enhancer, Matrix tablet

\section{INTRODUCTION}

Optimization of the dosage form characteristics within the inherited constrains of the gastrointestinal physiology requires during the development of oral control release drug delivery system (CRDDS). A typical controlled release system is designed to provide constant or nearly constant drug levels in plasma with reduced dose, frequency of administration and fluctuations in plasma concentrations via slow release over an extended period of time. ${ }^{1}$ It is important especially in the case of antihypertensive agents to maintain constant blood levels, as otherwise dose dumping may cause hypotension. ${ }^{2}$

Correspondence to: Abu Shara Shamsur Rouf Cell: +8801916670403

Email: rouf321@yahoo.com

Dhaka Univ. J. Pharm. Sci. 16(1): 43-53, 2017 (June)
Carvedilol is a vasodilating non-cardio selective $\beta$ blocker. This compound seems to give the opportunity for clinician to use a cardio protective agent without the concerning hemodynamic and metabolic actions of traditional $\beta$-blocker therapy. In contrast with conventional $\beta$-blockers, carvedilol maintains cardiac output, has a less extended effect on heart rate and reduces BP by decreasing vascular resistance. ${ }^{3}$ Conventional tablet dosage form of carvedilol is used to treat mild-to-moderate hypertension and angina pectoris. $^{4}$ Carvedilol is rapidly and extensively absorbed following oral administration, with an absolute bioavailability of approximately 25 to $35 \%$ due to a significant degree of first-pass metabolism. ${ }^{5}$ The half-life of carvedilol is between 7 and 8 hours. ${ }^{6}$ Therefore, conventional tablets are required to be administered 3-4 times a day. A suitable sustained release dosage form of carvedilol should provide 
prolonged action and better compliance by the patient. Carvedilol base is practically insoluble in water $(0.583 \mathrm{mg} / \mathrm{l})$ and very poor aqueous solubility indicates that its absorption is dissolution rate-limited (Figure 1). ${ }^{2}$ A phosphate salt of carvedilol is developed with improved aqueous solubility and chemical stability by protonation of the secondary amine as a salt. ${ }^{7}$

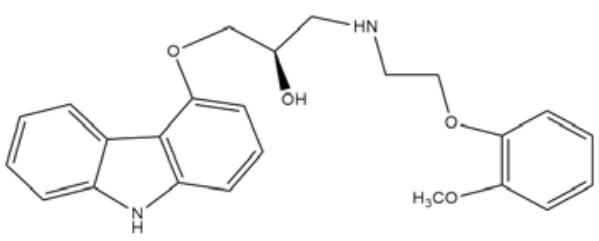

Figure 1. Chemical structure of Carvedilol.

Hydrophilic polymer matrix systems are widely used in oral controlled drug delivery to obtain a desirable drug release profile, costeffectiveness and broad regulatory acceptance. ${ }^{8}$ Hydroxypropylmethylcellulose (HPMC) is the excipient of choice for the preparation of hydrophilic matrix system because of its ability to control initial release most probably due to its claim as a fast gel formation, and formation of strong, viscous gel to control drug release. ${ }^{9}$ Although HPMC potentially retards the release of soluble drug, it also facilitates the release of relatively insoluble drugs (e.g. hydrochlorthiazide). In this case insolubility of drug molecule would be the main deterrent in the release and the solubilizing effect of HPMC would facilitate the release. The overall result is controlled drug delivery for a prolonged period of time. ${ }^{10}$ The effect of different fillers on release pattern of carvedilol from control release oral matrix tablet using cellulose ether polymer as drug release retardant has been reported. ${ }^{11}$ The aim of the present work was to prepare sustained release hydrophilic matrix tablets of carvedilol with SLS as dissolution enhancer and to study the in-vitro release characteristics of the prepared formulations.

\section{MATERIALS AND METHODS}

Materials. Carvedilol phosphate was obtained as a gift sample from Beximco Pharmaceuticals Limited, Bangladesh. Methocel ${ }^{\circledR}$ K4M CR, methocel ${ }^{\mathbb{R}}$ K15M CR and avicel PH101 (Dow Chemical's Asia Pvt, Limited, India), starch $1500^{\circledR}$ (Colorcon, USA), SLS (SigmaAldrich Chemie GmbH, Germany), talc (S.D. FineChem Limited, Mumbai, India) and magnesium stearate (Novochem, GmbH, Germany) were procured from local market. All other required chemicals were of reagent grade and distilled water was used throughout the experiment.

Preparation of matrix tablets. The active ingredient, release retardants, fillers, lubricant and glidant were blended together by dry mixing and made into tablets by direct compression at a definite compression force. The formulations of the tablets with their codes are listed in table 1-2. The characteristic of the formulations in table 1 is that, the amount of matrix forming polymer decreases gradually for each set of formulation and the reduced amount was replaced by filler. The formulations depicted in table 2 were prepared using variable percentages of SLS as dissolution enhancer with a fixed ratio of polymers. In all cases, the amount of the active ingredient is $80 \mathrm{mg}$ and the total weight of the tablet is $300 \mathrm{mg}$. The active ingredient, matrix forming polymers, fillers, magnesium stearate, talc and SLS were properly weighed and passed through a sieve of mesh size \#24. The weighed API and excipients (except magnesium stearate and talc) blended in a laboratory mixer without or with SLS (as in table 1-2) for about 10 minutes. Finally, magnesium stearate and talc were added and blended for another 2 minutes. The appropriate amounts of the blended mass were then compressed using a Perkin-Elmer laboratory hydraulic press equipped with a $10 \mathrm{~mm}$ flat faced punch and die set at a compression force of 5 tons and compression time of 30 seconds. The surfaces of the die and punch were lubricated before compression with magnesium stearate. For further study all the preparations were stored in airtight polyethylene bag at room temperature. This method of tablet production described by several authors has 
provided reproducible experimental results in terms of in vitro release. ${ }^{12,13}$

\section{Evaluation of physical properties of compression blends}

Angle of repose. The angle of repose of compression blends was determined by the funnel method. Accurately weighed powder mixtures were taken in a funnel and the height of the funnel was adjusted in such a way that the tip of the funnel just touched the apex of the heap of the powders. The powder mixtures were allowed to flow through the funnel freely onto the surface and the diameter of the powder cone was measured. The angle of repose was calculated using the following equation ${ }^{14}$ :

$$
\text { Angle of repose, } \theta=\tan ^{-1}(\mathrm{~h} / \mathrm{r})
$$

Where, $\mathrm{h}$ and $\mathrm{r}$ are the height and radius in $\mathrm{cm}$ of the powder cone.

Bulk density. Both loose bulk density (LBD) and tapped bulk density (TBD) were determined. A quantity of 2 gm of compression blend from each proposed formulation, previously lightly shaken to break any agglomerates formed, was introduced into a $10 \mathrm{ml}$ measuring cylinder. After the initial volume was observed, the cylinder was placed into the tap density tester set to a fixed rpm. The tapping was continued until no further change in volume was noted. Using the following equations LBD and TBD were calculated ${ }^{15}$ :

LBD $=$ Weight of the powder/volume of the packing.

TBD $=$ Weight of the powder/tapped volume of the packing.

Compressibility index. The compressibility index of the powder blend was determined by Carr's compressibility index ${ }^{16}$ :

Carr's index $(\%)=[(\mathrm{TBD}-\mathrm{LBD}) \times 100] / \mathrm{TBD}$

Hausner ratio. The Hausner ratio of the compression blends was determined by the following equation:

Hausner ratio $=$ tapped bulk density/loose bulk density
Total porosity. Total porosity was determined by measuring the volume occupied by a selected weight of powder $\left(\mathrm{V}_{\text {bulk }}\right)$ and the true volume of granules (the space occupied by the powder exclusive of spaces greater than the intermolecular space $(\mathrm{V})^{17}$ :

Porosity $(\%)=\left(\mathrm{V}_{\text {bulk }}-\mathrm{V}\right) / \mathrm{V}_{\text {bulk }} \times 100$.

Moisture content. About $1 \mathrm{gm}$ of compression blend was weighed and heated for 3 hours at $105^{\circ} \mathrm{C}$ in an oven. The moisture content as $\% \mathrm{w} / \mathrm{w}$ was determined by the following equation:

Moisture content $(\%)=[($ Initial weight - Final weight $)$ $/$ Initial weight $] \times 100$

\section{Evaluation of physical properties of tablets}

Weight variation test. To study weight variation, 20 tablets from each formulation were weighed using an electronic balance (Sartorius, Germany) and the test was performed according to the official method (BP).

Hardness and friability. For each formulation, the hardness and friability of 6 tablets were determined using the Dr. Schleuniger Pharmatron Tablet Tester (Model 6D, USA) and Erweka Friability Tester (Germany), respectively.

Thickness. The thickness of the tablet was determined using Dr. Schleuniger Pharmatron Tablet Tester (Model 6D, USA). Five tablets from each batch were used and average values were calculated.

\section{In vitro drug release studies of tablet matrices}

Preparation of calibration curve. About $10 \mathrm{mg}$ of carvedilol was taken in a clean and dry $50 \mathrm{ml}$ volumetric flask. $1 \mathrm{~mL}$ of methanol was added and shaken thoroughly to dissolve the drug and then sonicated for $5 \mathrm{~min}$ for complete dissolution of drug. The solution was allowed to cool at room temperature and then the volume was made up to the mark with distilled water. The solution was filtered through Whatman filter paper (No. 42) and then finally filtered through $0.45 \mu \mathrm{m}$ disk filter. The standard solutions of $1.0 \mu \mathrm{g} / \mathrm{ml}$ to $8.0 \mu \mathrm{g} / \mathrm{ml}$ were prepared with suitable dilution standard stock solution and the absorbance values were determined by the double beam spectrophotometer (Shimadzu, Japan) at $241 \mathrm{~nm}$. A 
Table 1. The active ingredient, polymer and excipients of formulations F1 to F4.

\begin{tabular}{lcccc}
\hline Component & F1 & F2 & F3 & F4 \\
\hline Carvedilol & 80 & 80 & 80 & 80 \\
Methocel K4M CR & 45 & 45 & 45 & 45 \\
Methocel K15M CR & 45 & 39 & 33 & 63 \\
Starch 1500 & 63 & 63 & 74 & 63 \\
Avicel PH101 & 62 & 2 & 2 & 80 \\
Mg- stearate & 2 & 3 & 3 & 2 \\
Talc & 3 & 300 & 300 & 3 \\
Total (in mg) & 300 & & & 300 \\
\hline
\end{tabular}

Table 2. The active ingredient, polymer, dissolution enhancers and other excipients of formulations F5 to F9.

\begin{tabular}{lccccc}
\hline Component & F5 & F6 & F7 & F8 & F9 \\
\hline Carvedilol & 80 & 80 & 80 & 80 & 80 \\
Methocel K4M CR & 45 & 45 & 45 & 45 & 45 \\
Methocel K15M CR & 33 & 33 & 33 & 33 & 33 \\
Starch 1500 & 63 & 63 & 63 & 63 & 63 \\
Avicel PH101 & 71 & 70.25 & 69.5 & 68.75 & 68 \\
SLS & 3 & 3.75 & 2.5 & 25 & 6 \\
Mg- stearate & 2 & 3 & 3 & 3 & 3 \\
Talc & 3 & 300 & 300 & 300 & 300 \\
Total (in mg) & 300 & & & \\
\hline
\end{tabular}

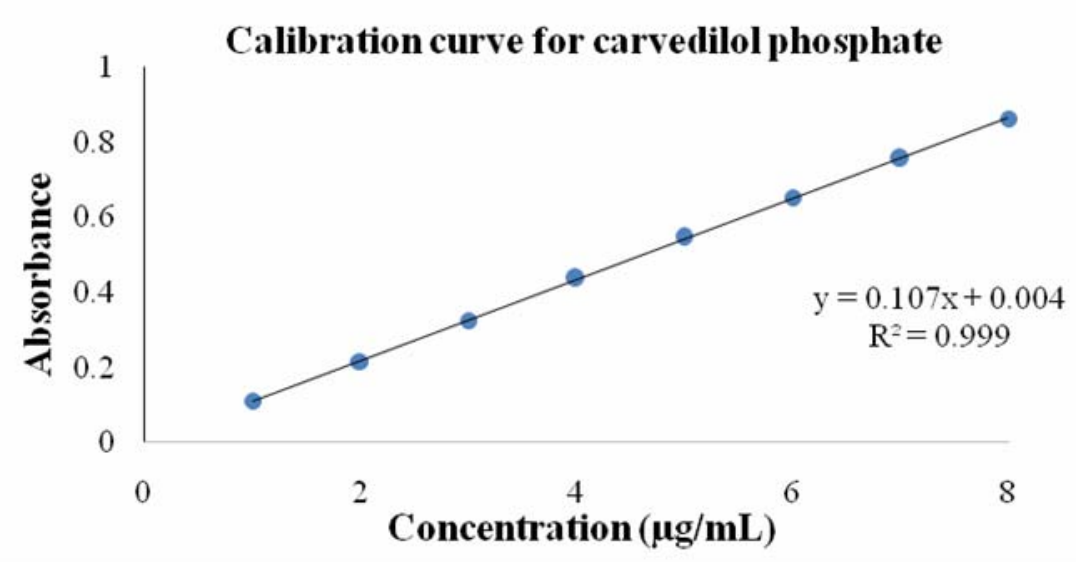

Figure 2. Calibration curve for carvedilol phosphate.

calibration curve was constructed by using absorbances and concentrations of standard solutions (Table 3 and figure 2).

Dissolution studies. The in vitro dissolution studies were conducted using USP apparatus type II (Electrolab, India) at $100 \mathrm{rpm}$ for $24 \mathrm{hrs}$. The dissolution medium was $900 \mathrm{ml}$ of $0.1 \mathrm{~N}$ simulated hydrochloric acid ( $\mathrm{pH} 1.2$ ) maintained at $37 \pm 0.05{ }^{\circ} \mathrm{C}$. The cumulative percentage of drug release at different time intervals $(1,2,4,8,12$ and $24 \mathrm{hrs})$ was measured by spectrophotometric method at $241 \mathrm{~nm}$ wavelength using the calibration curve of standard solution. 
Table 3. Absorbance values for standard solutions of carvedilol phosphate.

\begin{tabular}{cc}
\hline Concentration $(\mu \mathrm{g} / \mathrm{ml})$ & Absorbance \\
\hline 1.0 & 0.112 \\
2.0 & 0.216 \\
3.0 & 0.327 \\
4.0 & 0.438 \\
5.0 & 0.547 \\
6.0 & 0.652 \\
7.0 & 0.756 \\
8.0 & 0.863 \\
\hline
\end{tabular}

Analysis of release data. The drug release rate from the tablet matrices was interpreted by different kinetics namely zero-order, first-order, Higuchi's equation, Korsmeyer-Peppas and Hixson-Crowell equations. However, the applicability of Higuchi's equation to matrix systems is constrained by two factors i.e. the influence of swelling of the matrix due to hydration and gradual erosion of the matrix. KorsmeyerPeppas et al. have introduced a well-known exponential equation to embrace these factors for explaining the drug release behavior from polymeric systems:

$$
M_{t} / M_{\alpha}=k t^{n}
$$

Where, $M_{t} / M_{\alpha}$ is the fractional drug release at time $\mathrm{t}, \mathrm{k}$ is a release rate constant incorporating the structural and geometric characteristics polymeric systems and the drug, and $\mathrm{n}$ is the diffusional exponent indicative of the mechanism of drug release. The value of $n=0.45$ indicates Fickian (Case I) release, $>0.45$ but $<0.89$ for non-Fickian (anomalous) release and 0.89 for Case II (Zero order) release and $>0.89$ for super case II type of release. Case II generally refers to the erosion of the polymeric chain and anomalous transport (NonFickian) refers to a combination of both diffusion and erosion controlled drug release. ${ }^{18}$ The $\mathrm{n}$ values for different formulations have been calculated from the above equation to identify the drug release mechanism. The constant $\mathrm{k}$, though is one of the measures of release rate, should not be used for comparison due to the differences in drug release kinetics and test conditions. Therefore, to characterize the drug release rate in different experimental conditions, mean dissolution time (MDT) was calculated from dissolution data according to Mockel and Lippold using the following equation. ${ }^{19}$

$$
M D T=(n / n+1) \cdot K^{-1 / n}
$$

\section{RESULT AND DISCUSSION}

Physical properties of compression blends. The results of angle of repose $\left(<30^{\circ}\right)$ indicated good flow properties of the powder blends which was further supported by lower values of Carr's index and Hausner ratio. The percentage porosity values of the powder blends indicated that the packing of the powder might range from close to loose packing and also further confirming that the particles were not of greatly different in sizes. The moisture content of the powder mixture was found to be satisfactory for optimal tableting behavior (Table 4).

Table 4. Physical properties of compression blends.

\begin{tabular}{ll}
\hline Parameters & Results \\
\hline Angle of repose $\left({ }^{\circ}\right)$ & $26.74 \pm 0.03$ to $29.25 \pm 0.03$ \\
Loose bulk density $(\mathrm{gm} / \mathrm{ml})$ & $0.43 \pm 0.02$ to $0.45 \pm 0.01$ \\
Tapped bulk density $(\mathrm{gm} / \mathrm{ml})$ & $0.52 \pm 0.04$ to $0.54 \pm 0.04$ \\
Carr's index $(\%)$ & $14.20 \pm 0.03$ to $20.86 \pm 0.04$ \\
Hausner ratio & $1.17 \pm 0.01$ to $1.26 \pm 0.03$ \\
Total porosity $(\%)$ & $13.58 \pm 0.01$ to $17.65 \pm 0.06$ \\
Moisture content $(\%)$ & 2.89 to 3.45 \\
\hline
\end{tabular}

Table 5. Physical properties of compressed tablet.

\begin{tabular}{ll}
\hline Parameters & Results \\
\hline Average weight (mg) & $297.5 \pm 0.10$ to $303.2 \pm 0.13$ \\
Hardness $\left(\mathrm{Kg} / \mathrm{cm}^{2}\right)$ & $8.9 \pm 0.03$ to $10.8 \pm 0.02$ \\
Friability (\%) & 0.15 to 0.34 \\
Diameter (mm) & 10 \\
Thickness (mm) & $3.53 \pm 0.01$ to $3.85 \pm 0.01$ \\
\hline
\end{tabular}

Physical properties of tablet matrices. All the tablet formulations showed acceptable pharmacotechnical properties and complied with the compendial specifications for weight variation and hardness. Tablet hardness is not an absolute indicator of strength. 
Another measure of a tablet's strength is friability. In the present study, the percentage friability for all the formulations was below $1 \%$ indicating that the friability is within the prescribed limits. It was found that all the formulations showed uniform thickness. The average percentage of deviation of all tablet formulations was found to be within the limit (Table 5).

In vitro drug release studies of tablet matrices. Six tablets from each formulation were used for dissolution studies and the drug release profile was monitored at 1 hour, 2 hours, 4 hours, 8 hours, 12 hours and 24 hours. The drug concentrations in dissolution sample solutions were determined by UV-visible spectrophotometer using the calibration curve of standard solution. The results of in vitro dissolution studies of the formulations $\mathrm{F} 1$ to $\mathrm{F} 4$ are shown in table 6 and figure 3 .

As there are no sustained release tablets of carvedilol phosphate available in the Bangladesh market, theoretical sustained release needed for once daily administration was calculated based on its pharmacokinetics as suggested by Wagner et al. ${ }^{20}$ The theoretical release profile calculation is important to evaluate the formulation with respect to release rates and to ascertain whether it releases the drug in a predetermined manner. ${ }^{21}$ According to the theoretical release pattern, a once-daily carvedilol should provide a release of NMT $25 \%$ in $1 \mathrm{hr}, 30-45 \%$ in $4 \mathrm{hrs}, 45-60 \%$ in $8 \mathrm{hrs}, 60-70 \%$ in $12 \mathrm{hrs}$ and NLT 90\% in $24 \mathrm{hrs}$.

Table 6. Zero order release profile of carvedilol for formulations F1 to F4 (Mean; n=6).

\begin{tabular}{lcccc}
\hline Time(hrs) & \multicolumn{4}{c}{ Cumulative \% of Drug Released } \\
\cline { 2 - 4 } & F1 & F2 & F3 & F4 \\
\cline { 2 - 4 } 0 & 0 & 0 & 0 & 0 \\
1 & 2.63 & 7.01 & 8.18 & 27.74 \\
2 & 4.39 & 10.26 & 11.43 & 41.63 \\
4 & 7.63 & 14.07 & 15.85 & 49.31 \\
8 & 22.83 & 29.58 & 35.42 & 57.82 \\
12 & 33.71 & 40.49 & 44.88 & 62.53 \\
24 & 51.01 & 56.59 & 59.54 & 63.72 \\
\hline
\end{tabular}

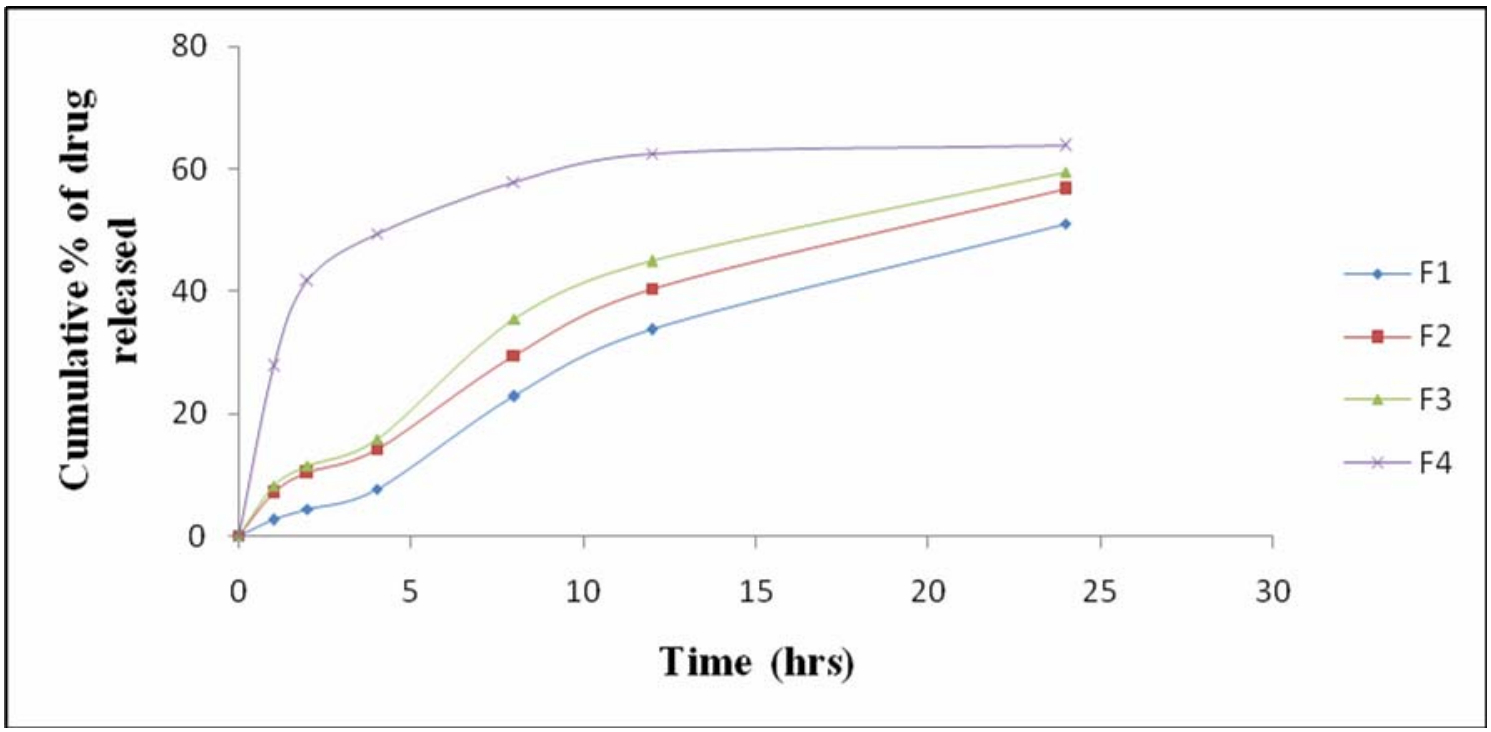

Figure 3. Zero order release profile of carvedilol for formulations F1 to F4 (Mean; $n=6$ ). 
According to table 6 and figure 3, in vitro release kinetics studies of these formulation indicated that decrease of percent composition of methocel K15M CR increases the release rate of drug from the tablet matrix but in case of formulation F4 initially gave burst release of drug which inferred that the drug and polymer interaction was not suitable for sustaining action up to 24 hours. On the other hand, this burst release of carvedilol in the initial hours, which is probably due to faster dissolution of the drug from the core and its diffusion out of the matrix forming the pores for the entry of solvent molecules. A suitable sustained release formulation should release the required amount of drug in the initial hour followed by slow release. Hence, initial burst release and high deviations in the release profile from the theoretical release pattern demonstrated the need for further development to find a suitable formulation to mimic the theoretical pattern.

Although formulation F3 showed increased release profile, it did not meet the theoretical dissolution profile for sustained release. To enhance dissolution rate five different formulations were developed using SLS as dissolution enhancer at variable percentages [F5 (1.0\%), F6 (1.25\%), F7 (1.5\%), F8 (1.75\%) and F9 (2.0\%)] with fixed ratio of methocel K4M CR \& methocel K15M CR (15\%:11\%). Six tablets from each formulation (F5-F9) were subjected to in vitro dissolution studies and the drug release profiles are shown in table 7 and figure 4.

Table 7. Zero order release profile of carvedilol for formulations F5 to F9 (mean; n=6).

\begin{tabular}{|c|c|c|c|c|c|}
\hline \multirow{2}{*}{ Time (hrs) } & \multicolumn{5}{|c|}{ Cumulative $\%$ of Drug Released } \\
\hline & F5 & F6 & F7 & F8 & F9 \\
\hline 0 & 0 & 0 & 0 & 0 & 0 \\
\hline 1 & 11.10 & 14.01 & 12.27 & 13.47 & 13.81 \\
\hline 2 & 17.82 & 19.86 & 18.98 & 18.92 & 17.85 \\
\hline 4 & 29.50 & 34.17 & 32.12 & 34.22 & 35.54 \\
\hline 8 & 47.02 & 53.15 & 51.11 & 53.15 & 55.46 \\
\hline 12 & 57.83 & 67.76 & 63.96 & 64.57 & 62.02 \\
\hline 24 & 81.40 & 98.42 & 96.38 & 98.14 & 98.25 \\
\hline
\end{tabular}

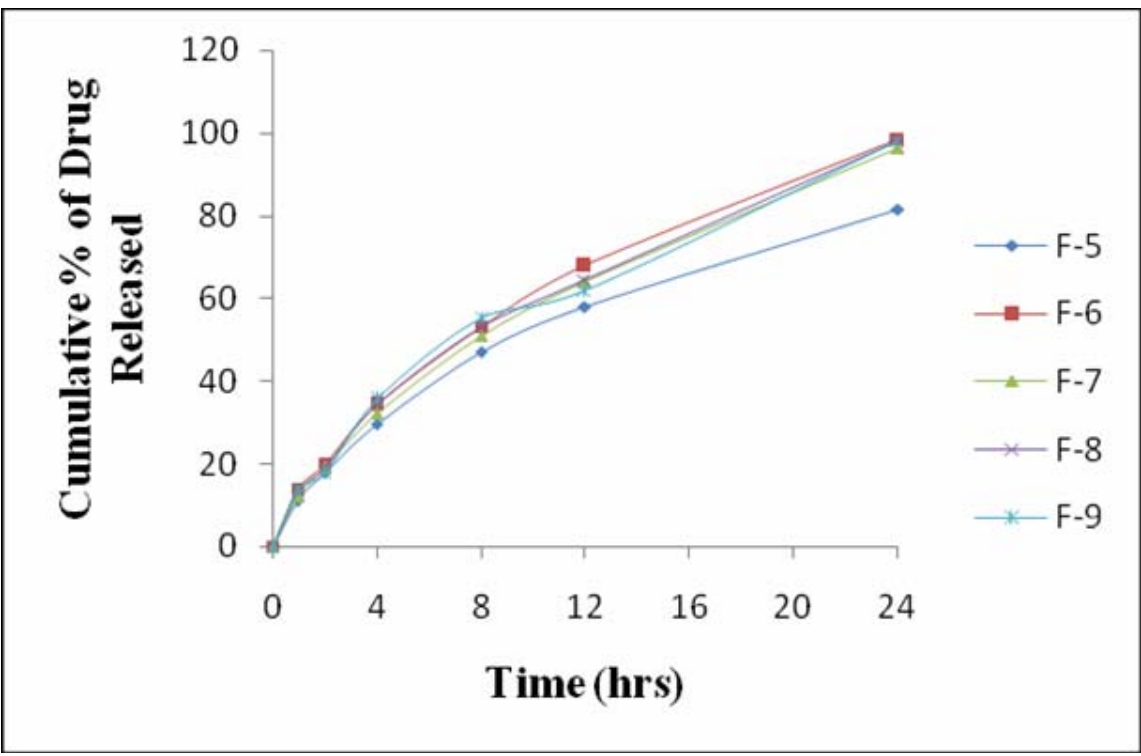

Figure 4. Zero order release profile of carvedilol for formulations F5 to F9 (mean; $n=6$ ). 


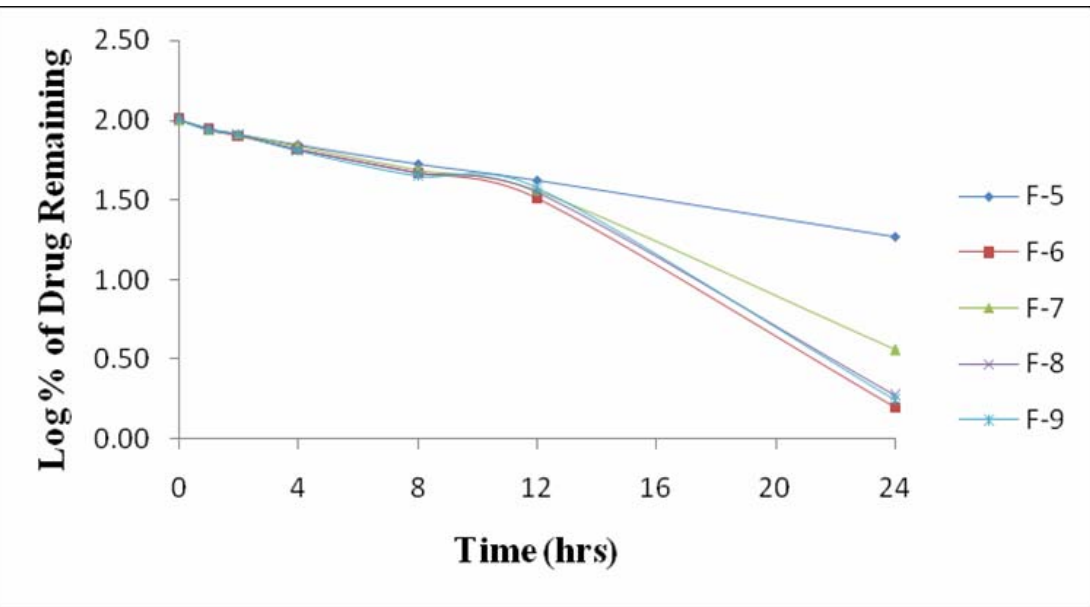

Figure 5. First order release profile of carvedilol for formulations F5 to F9 (mean; $n=6$ ).

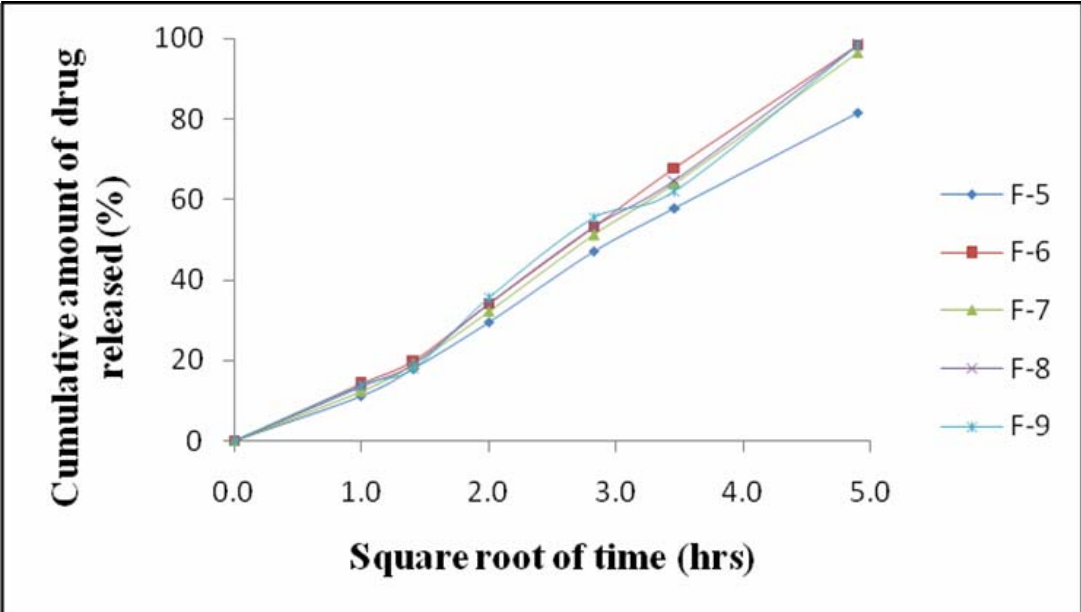

Figure 6. Higuchi's release profile of carvedilol for formulations F5 to F9 (mean; $\mathrm{n}=6$ ).

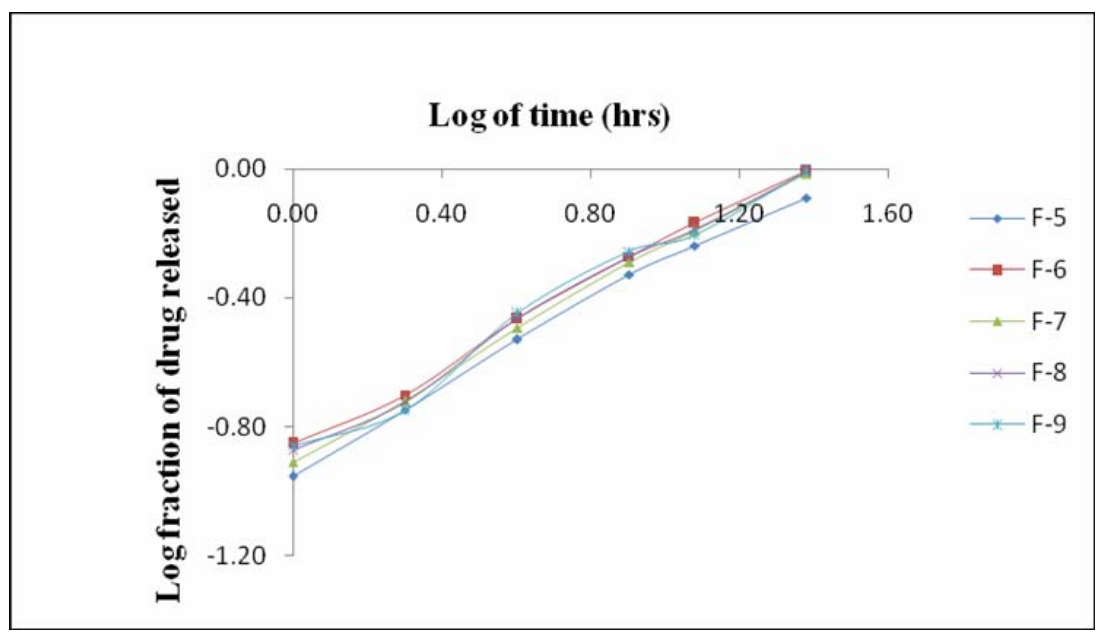

Figure 7. Korsmeyer-Peppas's release profile of carvedilol for formulations F5 to F9 (mean; $n=6$ ). 


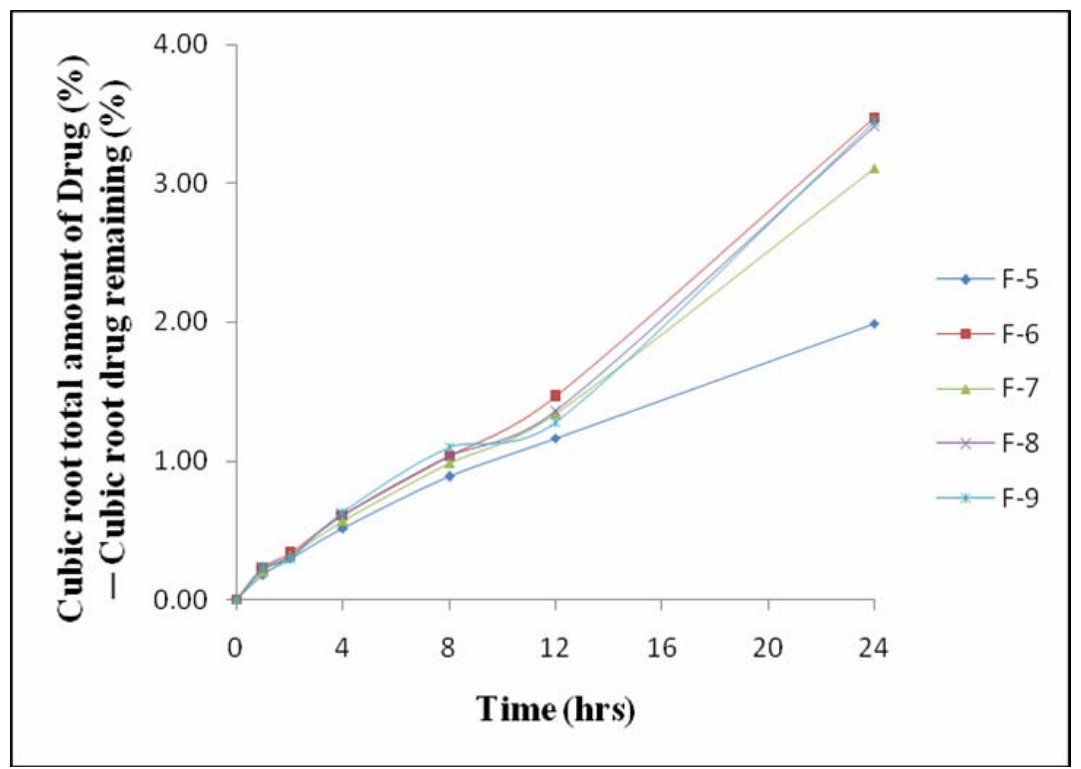

Figure 8. Hixson-Crowell's release profile of carvedilol for formulations F5 to F9 (mean; n=6).

Table 8. The release kinetic parameters of formulated tablets of carvedilol (F5- F9).

\begin{tabular}{|c|c|c|c|c|c|c|c|c|c|c|}
\hline \multirow{2}{*}{ Formulation } & \multicolumn{2}{|c|}{ Zero order } & \multicolumn{2}{|c|}{ First order } & \multicolumn{2}{|c|}{ Higuchi } & \multicolumn{2}{|c|}{ Korsmeyer-Peppas } & \multicolumn{2}{|c|}{ Hixson- Crowell } \\
\hline & $\mathrm{K}_{0}$ & $\mathrm{R}^{2}$ & $\mathrm{~K}_{1}$ & $\mathrm{R}^{2}$ & $\mathrm{~K}_{\mathrm{h}}$ & $\mathrm{R}^{2}$ & $\mathrm{n}$ & $\mathrm{R}^{2}$ & $\mathrm{~K}_{\mathrm{HC}}$ & $\mathrm{R}^{2}$ \\
\hline F5 & 3.243 & 0.923 & -0.029 & 0.997 & 17.35 & 0.992 & 0.638 & 0.994 & 0.080 & 0.984 \\
\hline F6 & 3.915 & 0.940 & -0.071 & 0.937 & 20.74 & 0.992 & 0.628 & 0.996 & 0.139 & 0.990 \\
\hline F7 & 3.843 & 0.949 & -0.057 & 0.955 & 20.24 & 0.990 & 0.655 & 0.997 & 0.125 & 0.993 \\
\hline F8 & 3.889 & 0.944 & -0.069 & 0.934 & 20.59 & 0.990 & 0.641 & 0.994 & 0.137 & 0.986 \\
\hline F9 & 3.867 & 0.937 & -0.069 & 0.926 & 20.44 & 0.985 & 0.638 & 0.983 & 0.136 & 0.979 \\
\hline
\end{tabular}

Table 9. Successive fractional dissolution times and MDT of formulations F-5 to F-9.

\begin{tabular}{ccccc}
\hline Formulation & $\mathrm{T}_{25 \%}$ & $\mathrm{~T}_{50 \%}$ & $\mathrm{~T}_{80 \%}$ & $\mathrm{MDT}$ \\
\hline F5 & 3.31 & 9.88 & 20.74 & 11.32 \\
F6 & 2.55 & 7.68 & 16.23 & 8.94 \\
F7 & 2.88 & 8.30 & 17.01 & 9.46 \\
F8 & 2.69 & 7.95 & 16.54 & 9.14 \\
F9 & 2.69 & 7.97 & 16.65 & 9.20 \\
\hline
\end{tabular}

When the data were plotted according to the first-order equation, the formulations showed a fair linearity with regression values between 0.926 and 0.997 (Figure 5 and table 8). Release of the drug from a matrix tablet containing hydrophilic polymers generally involves factors of diffusion. Diffusion is related to transport of drug from the tablet matrix into the in vitro dissolution medium depending on the concentration. In our experiments, the in vitro release profiles of drug from all the formulations could be best expressed by Higuchi's equation, as the plots showed high linearity $\left(\mathrm{R}^{2}: 0.985\right.$ to 0.992 ) as shown in figure 6 and table 8 . The data were fit into Korsmeyer-Peppas's equation to confirm the diffusion mechanism. The formulations F5 to F9 showed good linearity $\left(\mathrm{R}^{2}: 0.983\right.$ to 0.997$)$, with slope 
(n) values ranging from 0.628 to 0.655 , indicating that a coupling of diffusion and erosion mechanisms- so-called anomalous diffusion (Figure 7 and table 8). The dissolution data was also plotted in accordance with Hixson-Crowell cube root law (Figure 8 and table 8 ). Applicability of data $\left(\mathrm{R}^{2}: 0.979\right.$ to 0.993$)$ indicates a change in surface area and diameter of tablets with the progressive dissolution of matrix as a function of time.

Successive fractional dissolution times and MDT of the formulations F5 to F9 are shown in table $9 . \mathrm{T}_{25 \%}, \mathrm{~T}_{50 \%}$ and $\mathrm{T}_{80 \%}$ were changed with the percent composition of dissolution enhancers. MDT value is used to characterize the drug release rate from the dosage form and the retarding efficacy of the polymer. A higher value of MDT indicates a higher drug retarding ability of the polymer and vice-versa. The formulations F6, F7, F8 and F9 were found to meet the theoretical dissolution profile. Due to lower percentage of SLS used, formulation F6 was considered as the best formulation. Therefore, the development and optimization of once daily carvedilol sustained release tablet were successful.

\section{CONCLUSION}

Carvedilol phosphate is an important drug in the treatment of hypertension and stable angina pectoris. In view of its superiority in the treatment of hypertension, the preparation of a suitable sustained release dosage form might increase the efficacy of treatment and patient compliance by producing desirable blood concentrations and by minimizing the incidence of adverse effects.

\section{ACKNOWLEDGEMENTS}

The authors are thankful to the authority of Beximco Pharmaceuticals Limited, Bangladesh for providing reference standard as well as working API of carvedilol phosphate. The authors are also indebted to Mr. Subrata Bhadra, Assistant Professor, Department of Pharmaceutical Technology, Faculty of Pharmacy, University of
Dhaka, Dhaka-1000, Bangladesh for his cordial support during the study.

\section{REFERENCES}

1. Reza, S.M., Quadir, M.A. and Haider, S.S. 2003. Comparative evaluation of plastic, hydrophobic and hydrophilic polymers as matrices for controlled-release drug delivery. J. Pharm. Sci. 6, 282-291.

2. Halder, S., Hasan, M., Das, B.K., Kabir, A.K.L. and Rouf, A.S.S. 2012. In vitro release study of carvedilol phosphate matrix tablets prepared with hydroxypropyl methylcellulose. Trop. J. Pharm. Res. 13, 379-386.

3. Stafylas, P.C. and Sarafidis, P.A. 2008. Carvedilol in hypertension treatment. Vasc. Health Risk Manag. 4, 23-30.

4. Tenero, D.M., Henderson, L.S., Charlotte, A. and Baidoo, M.M. 2006 Pharmacokinetic properties of a new controlled release carvedilol. Am. J. Cardiol. 98, 5L-16L.

5. Kalimuthu, S. and Yadav, A. V. 2009. Formulation and evaluation of carvedilol loaded Eudragit E 100 nanoparticles. Int. J. Pharm. Tech. Res. 1, 179-183.

6. Joseph, J., McPhillips, Schwemer, G.T., Scott, D.I., Zinny, M. and Patterson, D. 1988. Effects of carvedilol on blood pressure in patients with mild to moderate hypertension. Drugs. 36, 8291

7. Chakarborty, S., Shukla, D., Jain, A., Mishra, B. and Singh, S. 2009. Assessment of solubilization characteristics of different surfactant for carvedilol phosphate as a function of $\mathrm{pH} . \mathrm{J}$. Col. Interface Sci. 335, 242-249.

8. Efentakis, M., Ronald, D.C. and Sonel, M.T. 2000. Development and evaluation of oral multiple unite and single unite hydrophilic controlled-release system. Pharm. Sci. Tech. 1, 34-38.

9. The Dow Chemical Company. 1987. Formulation for controlled release with METHOCEL cellulose ethers, USA.

10. Cabelka, T.D. and Sheskey, P.J., Evaluation of granulation, excipient characteristics and drug solubility in the preparation of hydrophilic controlled-release matrix tablets. Dow Chemicals Publications. [http: //www.dow.com]

11. Nalluri, B. N., Jyotheermayi, D., Anusha D. and Maheswari K. M. 2012. Controlled release tablet formulations of carvedilol. $J$. Chem. Pharm. Res. 4, 4266-4274.

12. Ritger, P.L. and Peppas, N.A. 1987. A simple equation for description of solute release II. Fickian and anomalous release from swellable devices. J. Control. Rel. 5, 37-42.

13. Shato, H., Miyagawa, Y., Okabe, T., Miyajima, M. and Sunada, H. 1997. Dissolution mechanism of diclofenac sodium from wax matrix granules. J. Pharm. Sci. 86, 929-934. 
14. Cooper, J. and Gun, C. 1986. In: Powder Flow and Compaction (Inc Carter SJ, eds. Tutorial Pharmacy), CBS Publishers and Distributors, New Delhi, India, pp. 211-233.

15. Shah, D., Shah, Y. and Rampradhan, M. 1997. Development and evaluation of controlled release diltiazem hydrochloride microparticles using cross-linked poly (vinyl-alcohol). Drug Dev. Ind. Pharm. 23, 567-574.

16. Aulton, M.E. and Wells, T.I. 1998. In: Pharmaceutics: The science of dosage form design, Churchill Livingston, London, England, pp. 247.

17. Martin, A. 2001. In: Micromeretics (Martin A, ed. Physical Pharmacy), Lippincott Williams and Wilkins, Baltimore, pp. 423-454.
18. Shato, H., Miyagawa, Y. and Okabe, T. 1997. Dissolution mechanism of diclofenac sodium from wax matrix granules. $J$. Pharm. Sci. 86, 929-934.

19. Mockel, J.E. and Lippold, B.C. 1993. Zero-order release from hydrocolloid matrices. Pharm. Res. 10, 1066-1070

20. Wagner, J.G. and Nelson, E. 1963. Percent absorbed time plots derived from blood level and/or urinary excretion data. $J$. Pharm. Sci. 52, 610-611.

21. Reddy, K.R., Mutalik, S. and Reddy, S. 2003. Once-daily sustained-release matrix tablets of nicorandil: Formulation and in vitro evaluation. AAPS Pharm. Sci. Tech. 4, 01-09. 